\title{
Evaluation of incidence frequency and analysis of risk factors for the occurrence of back pain in a randomly-chosen group in the Podkarpackie Region of south-eastern Poland
}

\author{
Mariusz Drużbicki' ${ }^{1}$ Grzegorz Przysada', Agnieszka Guzik², Andrzej Kwolek², Sławomir Snela', \\ Iwona Opalińska', Piotr Matłosz ${ }^{2}$ \\ ${ }^{1}$ Faculty of Medicine, Institute of Physiotherapy Rzeszów University, Clinical Department of the Regional Hospital No.: 2 \\ in Rzeszów, Poland \\ ${ }^{2}$ Faculty of Medicine, Institute of Physiotherapy Rzeszów University, Poland
}

Drużbicki M, Przysada G, Guzik A, Kwolek A, Snela S, Opalińska I, Matłosz P. Evaluation of incidence frequency and analysis of risk factors for the occurrence of back pain in a randomly-chosen group in the Podkarpackie Region of south-eastern Poland. Ann Agric Environ Med. 2016; 23(2): 335-340. doi: 10.5604/12321966.1203901

\begin{abstract}
Objective. The aim of the study was to evaluate the frequency of incidence and analysis of the risk factors for the occurrence of back pain (BP) in a group of professionally active inhabitants of the Podkarpackie Region of south-east Poland.

Materials and method. The study was carried out with a method of social survey on a randomly selected group of 2,000 the inhabitants of the Podkarpackie Region, age: 30-50 years. In the study group, $71.5 \%$ people reported back pain, $61 \%$ of whom indicated the pain being located in the lumbar-sacral region.

Results. It was shown that the chief factors increasing the frequency of occurrence of BP was the physical character of work connected with lifting heavy loads, as well as long-term work in one position with continual repetition of the same movements. The persons reporting BP were more frequently those who opted for passive forms of relaxation $(p=0.0280)$, and the difference was significant. No significant relationship was found between body stature and the frequency of incidence of BP ( $p=0.6327)$. In the study group, there was no relationship found between the frequency of occurrence of spinal pain syndrome (SPS) and the living environment.

Conclusions. In the study group of the randomly selected working inhabitants of the Podkarpackie Region, it was shown that the frequency of incidence of back pain is on the same level as in the other regions of the country. In the study group, the living environment was found not to have any significant influence on the frequency of back pain.
\end{abstract}

\section{Key words}

back pain, epidemiology, type of work, physical activity, living environment

\section{INTRODUCTION}

Back pain (BP) constitutes one of the most frequent dysfunctions of the human motor organ. The frequency of occurrence places BP in the group of the main civilisation diseases worldwide, not only in highly developed countries, but also among those with a lower economic status $[1,2]$.

The problem of pain syndromes concerns not only adults, but also children and teenagers [3]. Pain syndromes are a cause of a significant reduction of functional ability and a large absenteeism among the professionally active group, which significantly affects the quality of life of the patients. Frequent medical leaves, long-term treatment and early retirement pose a significant economic burden for many societies [4]. It is currently assumed that almost $80 \%$ of society, at various stages of their lives, suffer from dysfunction of the spine and peri-articular tissues. The chief location of these ailments is the lumbar section of the spine, while the cervical and thoracic spine account for approximately $20 \%$ of all spinal pain syndromes $[5,6]$.

Address for correspondence: Agnieszka Guzik, Faculty of Medicine, Institute of Physiotherapy Rzeszów University, Rymanowska 25/17, 35-083 Rzeszów, Poland E-mail: agnieszkadepa2@wp.pl

Received: 09 February 2014; accepted: 22 May 2014
The causes for BP may result from the dysfunctions of many structures within the functional spinal units. It is generally assumed that as little as only $5-15 \%$ of all causes of BP have a specific cause, such as a developmental defect, fracture or inflammation, while $85-95 \%$ cases of BP do not have a definite, specified cause, in which case it is defined as non-specific back pain syndrome [7].

The frequency of occurrence of BP depends on environmental factors and personal features. The factors which cannot be modified are age and gender. The frequency of incidence increases in the third decade of life and intensifies at the age of 60-65 years. In the majority of studies, no significant influence of gender on the frequency of incidence of BP was found, but it was shown that elderly men suffer more frequently from this syndrome than elderly women $[8$, $9,10]$. Heuch showed that a risk factor of the occurrence of BP is high body mass and BMI exceeding 30 [11]. Psycho-social factors, such as stress, anxiety, depression, lack of support and high requirements, are important risk factors for the occurrence of BP [12].

In general terms, the main causes of $\mathrm{BP}$ occurrence are a sedentary lifestyle, lack of physical activity, resulting in muscle weakening, as well as incorrect body posture, incorrect load on the spine during physical work, repetition of some movements, and traumas. All these factors contribute 
to the progress of degenerative overload changes of the spine, leading to the increase of pain and limitation of mobility [7, 8]. Bakker, on the basis of a systematic survey of studies in this field, has shown that the way of spending free time, physical activity, long-term sedentary or standing position, are not connected with BP, while such factors as heavy physical work, flexion position at work are not sufficiently proven as the factors causing the occurrence of BP [13].

\section{OBJECTIVE}

The aim of the study was to evaluate the frequency of occurrence of SPS among the inhabitants of the Podkarpackie Region of south-east Poland, with special consideration for the living environment of the subjects. An additional objective was also to determine the influence of such factors as age, gender, body stature, type of work performed, and the method of relaxation after work on the frequency of occurrence of spinal pain syndromes.

\section{MATERIALS AND METHOD}

A cohort study was performed in 2010 among a randomlyselected group of the inhabitants of the Podkarpackie Region. The eligible subjects were permanent residents of the Region, in the age group 30 - 50 years, counting from the date of examination. After the consent of the Department of Population of the Regional Board in Rzeszów, and in accordance with the principle of the protection of personal data, a group of 2,000 subjects were selected randomly via software (1,000 women and 1,000 men). A questionnaire was sent to each subject by post. 180 questionnaires were returned unanswered on account of change of place of residence or a wrong address; 551 questionnaires were answered and returned (27.6\% of all the questionnaires sent); 81 questionnaires contained mistakes or were incompletely filled in; 470 questionnaires were answered in a complete and correct way. Within some further analysis, unemployed subjects were excluded from the study $-11.5 \%(n=54)$, as well as subjects with history of spine and lower limbs traumas, surgical treatment of the spine, with faulty postures and scoliosis $(\mathrm{n}=19 ; 4.6 \%)$. After the above criteria were taken into consideration, 397 subjects were qualified into the study.

The study was carried out by means of social survey carried out with a questionnaire devised by a team at the Physiotherapy Institute of the Faculty of Medicine at the Medical University in Rzeszów. The questionnaire contained 43 closed questions concerning the following issues: frequency of occurrence and location of the back pain, type of work performed, amount of load in the currently performed occupation, method of relaxation and recreational physical activity, and use of medical leaves during the treatment of spinal pain syndrome. The main study was preceded by a pilot study, the aim of which was to evaluate the level of comprehension of the questions and the repetitiveness of answers.

The occurrence of BP in the study group was evaluated on the basis of the answer to the question: 'Did you experience back pain within the last 12 months?' The subjects had a choice of YES or NO answer [14]. In order to determine the location, the subjects were asked to point out the location of the main ailments, choosing from the lumbar, pectoral and cervical areas. The subjects were also asked about the type of the work performed (physical, mental, mixed), and about the load resulting from carrying heavy loads at work (answers: large loads exceeding $10 \mathrm{~kg}$, moderate loads: 3-9 kg, small loads up to $3 \mathrm{~kg}$, and no loads at all). The next question concerned the characteristics (manner of performance) of movement (physical activity) during work (answers: multiple repetition of the same movement, staying in the same position). The working time was divided in the questions into the working time within one day (answers: up to 5 hours, $6-8$, more than 8 ) and the number of workdays in a week (answers: 3-4 days per week, 5 days, 6-7 days). The subjects were also asked whether their work is connected with stress (answers: yes/no)

In the evaluation of the way of spending free time and relaxation, the subjects were asked about their preferred way of relaxing, with the choice of one answer from the two provided: 'I relax in a passive way: in sedentary or lying down position', or 'in an active way: walking, active recreation'. The subjects were asked about the frequency of active forms of relaxation (at least three times a week, once a week, rarely).

Statistical analysis. Comparative analysis of both groups was presented in the form of a summary of the number and percentage structure of the answers to the selected questions in the compared study groups (crosstabs or contingency tables). In order to evaluate to what degree the differentiation of answers within the study group reflects also some regularity observed in the entire target population, and also to what degree this could only be a question of incidental and random differences, statistical inference methods had to be applied (so-called tests of statistical significance). In particular, the nominal, (text) character of the compared characteristics determines the choice of a chi-square test. In the case of a comparison of the numerical characteristic (age, BMI), selected descriptive statistics were used, while statistical induction was based on the Mann-Whitney U test.

\section{RESULTS}

The total number of the subjects qualified to the study was 397. In the study group, 193 persons lived in urban areas and 204 in rural areas. No statistical differences were found between the inhabitants of urban and rural areas as far as gender, age, and stature were concerned.

In the case of urban dwellers, the average BMI value was 25.0, and $25.7(\mathrm{p}=0.2045)$ in the case of the subjects living in rural areas (Tab. 1).

Frequency of occurrence, location and treatment of back pain (BP). A positive answer to the question whether the subject had experienced back pain within the last 12 months was given by $285(71.8 \%)$ of the study subjects. The pain most frequently occurred in the lumbar segment of the spine (Fig. 1).

There were no statistically significant differences in the frequency of occurrence of BP between the inhabitants of rural and urban areas $(p=0.4605)$. The only difference concerned the frequency of occurrence of pain in the cervical spine area $(\mathrm{p}=0.0155)$, which occurred with every third inhabitant of a city, and almost every fifth inhabitant of a 
Table 1. Characteristics of study groups

\begin{tabular}{|c|c|c|c|c|c|}
\hline \multirow{2}{*}{ Gender } & \multicolumn{3}{|c|}{ Place of residence $(p=0.0707)$} & & \multirow{2}{*}{ Total } \\
\hline & \multicolumn{2}{|c|}{ Urban areas } & Rural areas & & \\
\hline Women & \multicolumn{2}{|c|}{$111(57.5 \%)$} & $138(67.6 \%)$ & & 249 \\
\hline Men & \multicolumn{2}{|c|}{$82(42.5 \%)$} & $66(32.4 \%)$ & & 148 \\
\hline Total & \multicolumn{2}{|c|}{193} & 204 & & 397 \\
\hline \multirow{2}{*}{ Place of residence } & \multicolumn{5}{|c|}{ Age [years] } \\
\hline & $\bar{x}$ & $\mathrm{Me}$ & $S$ & $\min$ & Max \\
\hline Urban areas & 40.8 & 41.0 & 6.5 & 30 & 60 \\
\hline Rural areas & 41.0 & 42. & 6.0 & 29 & 50 \\
\hline$p_{k-w}$ & & & 0.6581 & & \\
\hline \multirow{2}{*}{ Place of residence } & \multicolumn{5}{|c|}{ BMI } \\
\hline & $\bar{x}$ & $\mathrm{Me}$ & $S$ & $\min$ & Max \\
\hline Urban areas & 25.0 & 24.8 & 3.8 & 17.3 & 35.0 \\
\hline Rural areas & 25.7 & 25.4 & 4.1 & 18.4 & 38.5 \\
\hline$p_{k-w}$ & & & 0.2045 & & \\
\hline
\end{tabular}

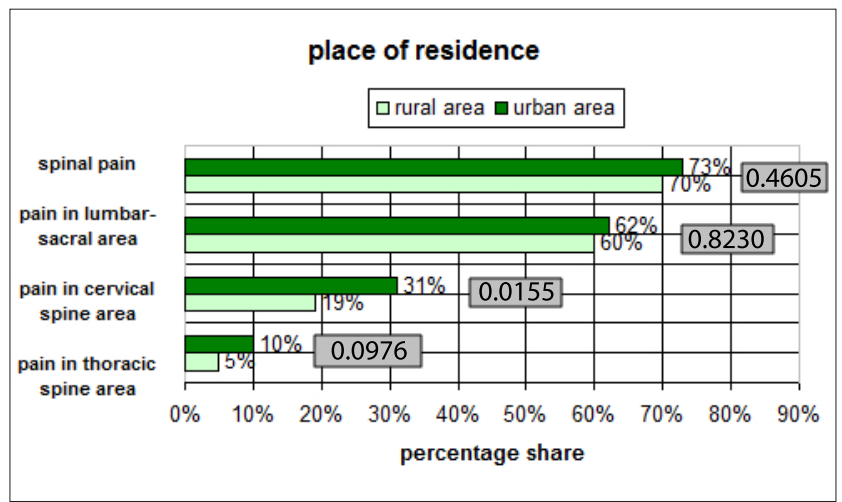

*) Values do not add up to $100 \%$ because subject could point to more than one location of pain

Figure 1. Location of back pain

village. Also, the location of BP in the thoracic spine area was more frequent among the inhabitants of urban areas; however, in this respect, in comparison with the inhabitants of rural areas, the difference was not statistically significant $(\mathrm{p}=0.095)$ (Fig. 1).

Among the subjects, the first incident of BP usually occurred at the age of 29 years $(\bar{x}=28.8 ; \mathrm{Me} 30.0)$. The earliest occurrence was at the age of 15 , whilst the latest - at the age of 50. In every fourth case the pain first occurred before 25 years of age and in every fourth after 35 years of age.

The number of subjects who decided to undergo medical treatment for BP was slightly larger among those living in urban areas $(55.2 \%)$ than in rural ones $(47.6 \%),(p=0.2694)$. Medical leaves were taken for the treatment of BP in the case of $35.1 \%$ subjects. In this respect, no statistical difference between the inhabitants of rural and urban areas was found in the medical leaves for the treatment of BP. Among urban dwellers, $34.3 \%$ of them used medical leaves during treatment, whereas among the inhabitants of rural areas this figure was $36.2 \%$ ( $p=0.7727)$. The most frequent time-span for a medical leave was two weeks $(15.1 \%)$ or more than two weeks (14.2\%). The number of one-week long medical leaves was only $3.9 \%$ of all cases, and those shorter than one week $-1.9 \%$.
Frequency of incidence of low back pain (LBP) depending on gender, age, body height and stature. It was found that LBP occurred with $60 \%$ of women and $62 \%$ of men. It was found that among people with LBP there were $62 \%$ of women and among people without LBP, women made up $64 \%$ of cases. The gender of the subjects had no significant influence on the frequency of incidence of back pain (result of the Chisquared test: $p=0.7522$ ). No statistically significant difference was found between the age of the subjects and the frequency of LBP $(p=0.1201)$.

Neither body height nor body stature (BMI) had any influence on the frequency of incidence of LBP. The mean value of BMI was 25.4 for people with LBP, and 25.2 $(p=0.6002)$ for subjects without it. An average body height in the case of LBP was 168.8 while for the persons without LBP it was168.1 $(p=0.4570)$.

BMI categorisation was made according to the generally applied criteria. LBP most frequently occurred among obese subjects, and was the least frequent among people with normal body stature as measured by their BMI. The difference was not significant statistically ( $p=0.6327)$ (Tab. 2).

Table 2. Evaluation of relationship between frequency of incidence of LBP in lumbar-sacral area and body stature

\begin{tabular}{lccc}
\hline \multirow{2}{*}{$\begin{array}{l}\text { Body stature categories BMI } \\
p=0.6327)\end{array}$} & \multicolumn{2}{c}{ LBP } & Total \\
\cline { 2 - 3 } & No & Yes & \multirow{2}{*}{187} \\
\hline Standard values & 78 & 109 & \\
\hline$\%_{\downarrow}$ & $50.3 \%$ & $45.04 \%$ & \\
\hline$\%_{\rightarrow}$ & $41.7 \%$ & $58.2 \%$ & \multirow{2}{*}{167} \\
\hline Overweight subjects & 62 & 105 & \\
\hline$\%_{\downarrow}$ & $40.0 \%$ & $43.4 \%$ & \\
\hline$\%_{\rightarrow}$ & $37.1 \%$ & $62.9 \%$ & 43 \\
\hline Obese subjects & 15 & 28 & \\
\hline$\%_{\downarrow}$ & $9.7 \%$ & $11.6 \%$ & $\mathbf{3 9 7}$ \\
\hline$\%_{\rightarrow}$ & $34.9 \%$ & $65.1 \%$ & \\
\hline Total & $\mathbf{1 5 5}$ & $\mathbf{2 4 2}$ & \\
\hline
\end{tabular}

Frequency of incidence of pain in the lumbar area and type of work. A statistically significant difference was found between the type of work performed and the frequency of incidence of LBP ( $p=0.0038)$. More than two-thirds of the subjects who declared performing physical work (blue collar workers) suffered from LBP, while among white collar workers the number of persons suffering from LBP in the lumbar-sacral area was less than a half (Tab. 3). In the environmental analysis, a significant difference concerning the type of work was found: among the inhabitants of rural areas, every second study subject performed physical work (50.3\%), whereas in the urban areas, physical work was performed by only $35.2 \%$ of the study subjects, and almost every second person had a white collar occupation (45.1\%), whereas only $22.8 \%$ of the inhabitants of rural areas declared to have such a type of work. The differences were statistically significant $(p=0.0003)$. At the same time, it was found that the frequency of incidence of LBP significantly depended on the size of the load to which the subjects were exposed at work. The heavier the load which must be lifted at work, the larger is LBP incidence. In the case of lifting heavy loads, exceeding $10 \mathrm{~kg}$, the share of persons with pain was $71.6 \%$, whereas in the group which declared that they did not carry 
any loads it was only $45.1 \%$. The differences between the studied groups were statistically significant $(p=0.0008)$. The inhabitants of rural areas were significantly more often exposed to carrying large and medium loads at work $-65.5 \%$ of the total number of the village dwellers within the study, compared with $47.2 \%$ of the dwellers of the cities $(p=0.0208)$.

Table 3. Evaluation of the relationship between incidence of LBP and type of work performed

\begin{tabular}{|c|c|c|c|}
\hline \multirow{2}{*}{$\begin{array}{l}\text { Type of work } \\
(p=0.0038)\end{array}$} & \multicolumn{2}{|c|}{ LBP } & \multirow{2}{*}{ Tota } \\
\hline & No & Yes & \\
\hline Physical & 53 & 118 & \multirow{3}{*}{171} \\
\hline$\%_{\downarrow}$ & $34.2 \%$ & $48.8 \%$ & \\
\hline$\%$ & $31.0 \%$ & $69.0 \%$ & \\
\hline Mental & 70 & 64 & \multirow{3}{*}{134} \\
\hline$\%_{\downarrow}$ & $45.2 \%$ & $26.4 \%$ & \\
\hline$\%$ & $52.2 \%$ & $47.8 \%$ & \\
\hline Mixed & 32 & 60 & \multirow{3}{*}{92} \\
\hline$\%_{\downarrow}$ & $20.6 \%$ & $24.8 \%$ & \\
\hline$\% \rightarrow$ & $34.8 \%$ & $65.2 \%$ & \\
\hline Total & 155 & 242 & 397 \\
\hline
\end{tabular}

The relationships between five characteristics typical for movement at work and the frequency of occurrence of LBP were studied. Among the subjects with LBP, the majority repeated the same movement with a load $(\mathrm{p}=0.0360)$. A relatively low test probability value was obtained for such a factor as 'staying in the same position with load for a long time', which also occurred more frequently among people with LBP (Tab. 4). In the study group, urban inhabitants more frequently indicated their professional work in a sedentary position and in standing with no load $(p=0.0155)$, whereas rural inhabitants referred to a repetitive movement with load ( $p=0.0066)$ (Tab. 4).

Table 4. Evaluation of frequency of LBP depending on type of work performed

\begin{tabular}{|c|c|c|c|c|c|c|c|c|c|c|}
\hline \multicolumn{5}{|c|}{ LBP } & \multirow{3}{*}{$p$} & \multicolumn{4}{|c|}{ Environment } & \multirow{3}{*}{$p$} \\
\hline & \multicolumn{2}{|c|}{ No } & \multicolumn{2}{|c|}{ Yes } & & \multicolumn{2}{|c|}{ Urban } & \multicolumn{2}{|c|}{ Rural } & \\
\hline & $\mathrm{N}$ & $\%$ & $\mathrm{~N}$ & $\%$ & & $\mathrm{~N}$ & $\%$ & $\mathrm{~N}$ & $\%$ & \\
\hline $\mathrm{a}$ & 30 & $19.4 \%$ & 70 & $28.9 \%$ & 0.0360 & 36 & $20.3 \%$ & 62 & $30.4 \%$ & 0.0066 \\
\hline b & 22 & $14.2 \%$ & 26 & $10.7 \%$ & 0.8433 & 26 & $10.5 \%$ & 26 & $12.7 \%$ & 0.2918 \\
\hline c & 37 & $23.9 \%$ & 44 & $18.2 \%$ & 0.5617 & 48 & $28.0 \%$ & 38 & $18.6 \%$ & 0.1362 \\
\hline d & 49 & $31.6 \%$ & 65 & $26.9 \%$ & 0.5995 & 69 & $42.0 \%$ & 48 & $23.5 \%$ & 0.0155 \\
\hline e & 17 & $10.9 \%$ & 37 & $15.3 \%$ & $0 ., 0787$ & 23 & $10.5 \%$ & 30 & $14.7 \%$ & 0.2257 \\
\hline
\end{tabular}

The number of working days within a week did not affect the frequency of occurrence of LBP - this can be concluded from comparison of the three groups of people selected on the basis of the questionnaire (3-4 days a week $-4.8 \%$ of total subjects, 5 days $-57.7 \%$ of total subjects, $6-7$ days $35.7 \%$ of total subjects). However, if this very small and not representative group of people working 3-4 days is neglected in the analysis, the result of a chi-square test may turn out to be statistically significant $(p=0.0433)$, and therefore it may be concluded that people working longer are more exposed at the risk of LBP. A statistically significant relationship was also shown between the working time within a day and the frequency of LBP. Persons with LBP amounted to $63 \%$ of all subjects working more than eight hours per day $(\mathrm{x}=9.5 \mathrm{~h} . ; \mathrm{Me}=9.0 \mathrm{~h})$, while in the group of people working up to eight hours a day, people with LBP. amounted to $53 \%$. The difference of the mean working time among people with LBP and the mean working time among people without LBP was statistically significant $(p=0.0056)$. Weekly working time of the subjects from rural and urban areas was similar. $65.2 \%$ urban dwellers and 52.1\% rural dwellers worked five days a week. 31 . $2 \%$ inhabitants of urban areas and $41.7 \%$ of rural ones declared working 6-7 days a week. The difference was not significant statistically $(p=0.0705)$.

Frequency of occurrence of LBP in relationship with the form of relaxation and recreational physical activity. Among all subjects, $75.6 \%$ declared that they relax in a passive way. In this group, people with LBP made up $64.7 \%$, while amongst persons preferring active forms of relaxation, people with LBP made up 50.6\% (Tab. 5). The difference was statistically significant $(p=0.0280)$. It was found that there was no statistically significant difference with regards to the forms of relaxation between the inhabitants of cities and rural areas $(p=0.4151)$. Passive forms of relaxation were chosen by $73.3 \%$ of rural inhabitants and $69.0 \%$ of urban dwellers, while active forms of relaxation were chosen by $31.0 \%$ urban inhabitants and $26.7 \%$ of rural ones. $(p=0.4151)$. The frequency of recreation exercises within a week was not proven to have any influence on the frequency of occurrence of BP $(p=0.8841)$.

Table 5. Evaluation of frequency of occurrence of LBP depending on form of relaxation and recreational physical activity

\begin{tabular}{|c|c|c|c|}
\hline \multirow{2}{*}{$\begin{array}{l}\text { Form of relaxation } \\
(p=0.0280)\end{array}$} & \multicolumn{2}{|c|}{ LBP } & \multirow{2}{*}{ Total } \\
\hline & No & Yes & \\
\hline Passive & 100 & 183 & \multirow{3}{*}{283} \\
\hline$\%_{\downarrow}$ & $64.5 \%$ & $75.6 \%$ & \\
\hline$\%$ & $35.3 \%$ & $64.7 \%$ & \\
\hline Active & 55 & 59 & \multirow{3}{*}{114} \\
\hline$\%_{\downarrow}$ & $35.5 \%$ & $24.4 \%$ & \\
\hline$\% \rightarrow$ & $48.2 \%$ & $51.8 \%$ & \\
\hline Total & 155 & 242 & 397 \\
\hline $\begin{array}{l}\text { Recreational physical activity in spare time } \\
(p=0.0192)\end{array}$ & \multicolumn{2}{|c|}{ LBP } & \\
\hline Yes & 103 & 125 & \multirow{3}{*}{228} \\
\hline$\%_{\downarrow}$ & $66.5 \%$ & $51.7 \%$ & \\
\hline$\% \rightarrow$ & $45.2 \%$ & $54.8 \%$ & \\
\hline No & 52 & 117 & \multirow{3}{*}{169} \\
\hline$\%_{\downarrow}$ & $33.5 \%$ & $48.3 \%$ & \\
\hline$\% \rightarrow$ & $30.8 \%$ & $69.2 \%$ & \\
\hline Total & 155 & 242 & 397 \\
\hline
\end{tabular}

\section{DISCUSSION}

Back pain is a civilisation disease which concerns a significant part of the world's society. The presented study shows that as much as $71.5 \%$ of the population investigated either are 
or have been affected by BP, and that the main location of pain was the lumbar segment of the spine. No statistically significant differences with regards to the occurrence of BP syndrome were found between the inhabitants of urban and rural areas. The only difference consisted in the frequency of occurrence of the pain syndrome in the cervical section of the spine, which involved almost every third urban inhabitant, but less than every fifth rural dweller. The location of BP in the thoracic area was also more frequent among the inhabitants of cities, although the difference in comparison with rural inhabitants was not as large, and therefore it was not statistically significant. Despite the lack of statistically significant differences, it was be observed that the inhabitants of rural areas, including farmers, perform the kind of work which might predispose them to more frequent occurrences of BP. In a study carried out in Sweden in a group of 1,013 farmers and 967 people performing other jobs, Holmberg found that pain in the area of arms, hip joints and lower part of the spine occurred with a more significant frequency among farmers [15].

The disorders of the function of the muscle-skeletal system, including spinal pain syndromes, constitute one of the main causes of medical leaves among the population of professionally active persons. The factors which predispose people to take medical leaves more often on account of BP, comprise the following: hard physical work, level of education and the type of employment. People who are self-employed, including farmers, take medical leaves less often and the leaves are much shorter [16]. In the study group of persons with BP, 31.5\% persons took medical leaves during the treatment of BP. Most frequently the duration of a medical leave was two weeks. There were no differences with regards to the frequency of the leaves between the inhabitants of rural and urban areas.

The basic cause of such a frequent incidence of this syndrome can be attributed to an immense and fast change in the contemporary lifestyle. Ghaffari observed that the type of occupation and physical work affects the frequency of BP in a significant way [17], while Lisiński, in his own study, observed that low back pain resulting from an overload with professional work can be found most often among those who are forced to lift and carry heavy loads at work, or are forced to perform repetitive bending and rotations of the spine [18]. The results of the presented study suggest that a patient with $\mathrm{BP}$ is usually a person performing physical work, most frequently in a static position, with multiple repetition of the same actions with a load, exposed to significant loads both in their current work and in the past. Load on the spine is not the only issue resulting from the type of work, but also from its duration. In the study group, persons with BP could be characterised by longer duration of work, both within one day and during the whole week.

Chenot studied a group of 1,432 subjects ( 778 women) with $\mathrm{BP}$ and found that women were more at risk of the occurrence of the spinal pain syndrome, and that they have poorer prognoses [19]. Schneider, when studying a representative groups of Germans in the age group between $20-64$, found that among people who reported that they experienced BP lasting longer than seven days, 32\% were men and $40 \%$ women [20]. Białachowski et al., in a study of 409 patients treated for low back pain, found that the male population was more often affected by the discussed syndromes. These authors also showed that low back pain concerned mostly people at productive age, between 30 - 55 years of age [21].

In the presented study, no significant influence of gender on the frequency of BP was found, both with respect to the entire group and with regards to the living environment. The frequency of occurrence increased with the age of the subjects, and was the highest in the group aged between $40-50$.

An important risk factor of BP is body stature. Many authors point to the fact that obesity, as manifested by a higher value of BMI, is related to a higher risk of the occurrence of pain syndrome, and that obesity predisposes the occurrence of chronic BP [22]. In the current study, overweight subjects and subjects with obesity comprised $54.8 \%$ of all patients with BP. No significant influence of the body stature on the frequency of BP occurrence was found, yet it must be stressed that the largest number of subjects with $\mathrm{BP}$ were among obese persons, and the least number among those with correct body stature (the norm as per BMI).

Strøyer found that physical activity is a very important factor in the prophylaxis of BP [23]. Brage emphasise that the patients with complaints of spinal pain syndromes are in a general poor emotional and physical condition which, in turn, has an effect on the occurrence and persistence of BP [24]. From the current study it can be seen that the majority of subjects with BP selected passive relaxation and the statistically significant difference in this respect allows the conclusion that active forms of relaxation decrease the risk of incidence of spinal pain syndrome. No significant difference was found, however, between the inhabitants of the urban and rural areas with regards to the forms of relaxation. Among those who did not perform any physical activity, almost two-thirds were affected by spinal pain syndromes, while among the active part of population only a half were affected. Maul, in his study comprising a group of 183 staff members of a hospital suffering from low back pain, proved that long-term physical training has great significance in the secondary prophylaxis of spinal pain syndromes. An increase of physical capacity, muscular strength and decrease in pain were observed, which suggests long-term benefits from physical training [25].

\section{CONCLUSIONS}

Spinal pain syndromes generally occur among the inhabitants of the Podkarpackie Region and constitute a cause of frequent work absenteeism.

In the study group it was shown that the gender and age of the study group, irrespective of the living environment, do not have any significant influence on the frequency of SPS occurrence - this feature rather tends to be affected by the duration of work.

The subjects who work longer than eight hours per day within a working day and for more than five days a week are more often affected by spinal pain syndromes.

The way of spending spare time is a predisposing factor for the occurrence of spinal pain syndromes.

The inhabitants of urban areas with preferences for active forms of relaxation are less frequently affected by spinal pain syndromes. 


\section{REFERENCES}

1. Landry MD, Raman SR, Sulway C, Golightly YM, Hamdan E. Prevalence and risk factors associated with low back pain among health care providers in a Kuwait hospital. Spine. 2008; 33: 539-545.

2. Waterman BR, Belmont PJ, Schoenfeld AJ. Low back pain in the United States: incidence and risk factors for presentation in the emergency setting. Spine J. 2012; 12: 63-70.

3. Kędra A, Czaprowski D. Epidemiology of back pain in children and youth aged 10-19 from the area of the southeast of Poland. Biomed Res Int. 2013; 2013: 506823

4. Steenstra IA, Verbeek JH, Heymans MW, Bongers PM. Prognostic factors for duration of sick leave in patients sick listed with acute low back pain: a systematic reviewof the literature. Occup Environ Med. 2005; 62(12): 851-60.

5. Hoy D, Bain C, Williams G, March L, Brooks P, Blyth F et al. A systematic review of the global prevalence of low back pain. Arthritis Rheum. 2012; 64(6): 2028-37.

6. Hoy D, Protani M, Buchbinder R. The epidemiology of neck pain. Best Pract Res Clin Rheumatol. 2010; 24(6):783-792.

7. Ehrlich GE. Low back pain. Bull World Health Organ. 2003; 81(9): 671-6.

8. Kopec JA, Sayre EC, Esdaile JM. Predictors of back pain in a general population cohort. Spine 2004; 29(1): 70-7.

9. Manchikanti L, Singh V, Datta S, Cohen SP, Hirsch JA. Comprehensive review of epidemiology, scope, and impact of spinal pain. Pain Physician. 2009; 12(4): E35-70.

10. Hicks GE., Morone N., Weiner DK. Degenerative lumbar disc and facet disease in older adults: prevalence and clinical correlates. Spine 2009; 34: 1301-6.

11. Heuch I, Heuch I, Hagen K, Zwart JA. Body mass index as a risk factor for developing chronic low back pain: a follow-up in the Nord-Trøndelag Health Study. Spine (Phila Pa 1976). 2013; 38(2): 133-9.

12. Linton SJ. Do psychological factors increase the risk for back pain in the general population in both a cross-sectional and prospective analysis? Eur J Pain. 2005; 9(4): 355-61.
13. Bakker EW, Verhagen AP, van Trijffel E, Lucas C, Koes BW. Spinal mechanical load as a risk factor for low back pain: a systematic review of prospective cohort studies. Spine (Phila Pa 1976). 2009; 34(8): E281-93

14. Hoy D, Brooks P, Blyth F, Buchbinder R. The Epidemiology of low back pain. Best Pract Res Clin Rheumatol. 2010; 24(6): 769-81.

15. Holmberg S, Stiernström EL, Thelin A, Svärdsudd K. Musculoskeletal symptoms among farmers and non-farmers: a population-based study. Int J Occup Environ Health. 2002; 8(4): 339-45.

16. Holmberg SA, Thelin AG. Predictors of sick leave owing to neck or low back pain: a 12-year longitudinal cohort study in a rural male population. Ann Agric Environ Med. 2010; 17(2): 251-7.

17. Ghaffari M., Alipour A., Jensen I., et al.: Low back pain among Iranian industrial workers. Occup Med. 2006; 56 (7): 455-460.

18. Lisiński P, Samborski W. Bóle kręgosłupa lędźwiowego w grupie zawodowej fizjoterapeutów. Balneol Pol. 2006; 3; 156-160.

19. Chenot JF, Becker, Leonhardt C, Keller S, Donner-Banzhoff $\mathrm{N}$, Hildebrandt J et al. Sex differences in presentation, course, and management of low back pain in primary care. Clin J Pain 2008; 24: 578-84.

20. Schneider S, Randoll D, Buchner M. Why do women have back pain more than men? A representative prevalence study in the federal republic of Germany. Clin Pain J. 2006; 22(8): 738-747.

21. BiałachowskiJT, Stryła W. Analiza wybranych cech antropometrycznych i rodzaju pracy zawodowej u chorych z przepukliną jądra miażdżystego części lędźwiowej kręgosłupa. Post Rehab. 2002; 16(1); 33-40.

22. Heuch I, Heuch I, Hagen K, Zwart JA. Body mass index as a risk factor for developing chronic low back pain: a follow-up in the Nord-Trøndelag Health Study. Spine 2013; 38 (2): 133-9.

23. Strøyer J, Jensen LD. The role of physical fitness as risk indicator of increased low back pain intensity among people working with physically and mentally disabled persons: a 30 -month prospective study. Spine 2008; 33(5): 546-54.

24. Brage S, Sandanger I, Nygård JF. Emotional distress as a predictor for low back disability: a prospective 12-year population-based study. Spine 2007; 32(2): 269-74.

25. Maul I, Läubli T, Oliveri M, Krueger H. Long-term effects of supervised physical training in secondary prevention of low back pain. Eur Spine J. 2005; 14(6): 599-611. 